\title{
COMPARATIVE STUDY OF PERCUTANEOUS DILATATIONAL TRACHEOSTOMY VERSUS STANDARD OPERATIVE TRACHEOSTOMY
}

\author{
D. Senthamarai Kannan', G. Soundara Rajan², P. V. Haridas ${ }^{3}$
}

${ }^{1}$ Assistant Professor, Department of ENT, Chengalpattu Medical College.

${ }^{2}$ Assistant Professor, Department of ENT, Chengalpattu Medical College.

${ }^{3}$ Associate Professor, Department of ENT, Chengalpattu Medical College.

ABSTRACT

\section{BACKGROUND}

The aim of this study is to compare intraoperative and postoperative complications of percutaneous dilatational tracheostomy and standard operative tracheostomy, advantages of Ciaglia's Blue Rhino dilator.

\section{MATERIALS AND METHODS}

This retrospective non-randomised comparative study done at Chengalpattu Medical College Hospital, fifty critically ill patients who were on endotracheal intubation and undergone percutaneous dilatational tracheostomy and standard operative tracheostomy between the year 2010 - 2015 were selected.

\section{RESULTS}

Fifty patients were included in this study, 25 for percutaneous dilatational tracheostomy and 25 for standard operative tracheostomy. The mean age was 37.7 yrs. - 39 were male and 11 were female. The mean duration of percutaneous dilatational tracheostomy was 9.6 minutes and standard operative tracheostomy was 22 minutes. Four patients developed major bleeding in standard operative tracheostomy, whereas none of percutaneous dilatational tracheostomy group patients encountered this complication. Post-operative complications were significantly high with standard operative tracheostomy (56\%) compared to percutaneous dilatational tracheostomy group (8\%).

\section{CONCLUSION}

In this comparative study of percutaneous dilatational tracheostomy and standard operative tracheostomy, we conclude that it is a faster technique and a safe alternative to standard operative tracheostomy. Intraoperative and postoperative complications are less with percutaneous dilatational tracheostomy.

\section{KEYWORDS}

Percutaneous Dilatational Tracheostomy, Standard Operative Tracheostomy, Ciaglia's Blue Rhino Dilator.

HOW TO CITE THIS ARTICLE: Kannan DS, Rajan GS, Haridas PV. Comparative study of percutaneous dilatational tracheostomy versus standard operative tracheostomy. J. Evolution Med. Dent. Sci. 2017;6(14):1066-1071, DOI: 10.14260/Jemds/2017/231

\section{BACKGROUND}

Tracheostomy is one of the oldest life-saving surgical procedure performed, which has been recorded in Egyptian papyrus as early as $100 \mathrm{BC}$. This is done for both elective and emergency purposes. Most of the modern day tracheostomy are performed on adult, intubated intensive care unit patients to provide long-term airway aces. There are definitive advantages of tracheostomy compared to prolonged translaryngeal intubation, which include improved patient comfort, effective airway suctioning, decreased airway resistance, ability to eat orally, more secure airway.

Percutaneous dilatational tracheostomy techniques are gaining greater popularity in intensive care units. It is faster and most safe alternative when using Ciaglia Single Blue Rhino dilator.(1) This can be easily performed as minimally invasive bedside procedure.(2)

Financial or Other, Competing Interest: None.

Submission 20-01-2017, Peer Review 06-02-2017,

Acceptance 08-02-2017, Published 14-02-2017.

Corresponding Author:

Dr. D. Senthamarai Kannan,

Assistant Professor,

Department of ENT,

Chengalpattu Medical College.

E-mail:dskannanent@gmail.com

DOI: $10.14260 /$ jemds $/ 2017 / 231$ percutaneous dilatational tracheostomy with standard operative tracheostomy performed in intensive care units. Government Chengalpattu Medical College Hospital, Chengalpattu. Numerous techniques have been developed since its evolution of which modified Ciaglia technique is safe, fast and easy to perform. It has lower incidents of postoperative bleeding(3) and infection. $(4,5,6)$ This technique is adopted for this study.

\section{Aims of Study}

1. To study the indications of tracheostomy in intensive care units.

2. To compare intraoperative and postoperative complications of percutaneous dilatational tracheostomy and standard operative tracheostomy.

3. To study the advantages of Ciaglia's Blue Rhino dilator.

4. To study post tracheostomy squealer of percutaneous dilatational and standard operative tracheostomy.

\section{MATERIALS AND METHODS}

This study was conducted at Medical and Surgical Intensive Care Units. This study was done after Institutional approval and informed written consent was obtained from all patients included in this study. 


\section{Study Design}

This retrospective non-randomised comparative study done at Chengalpattu Medical College Hospital, fifty critically ill patients who were on endotracheal intubation and undergone percutaneous dilatational tracheostomy and standard operative tracheostomy between the years 2010 - 2015 were selected.

\section{Percutaneous Dilatational Tracheostomy Group (PDT)}

Twenty-five patients in this group has undergone percutaneous dilatational tracheostomy using Ciaglia Blue Rhino Dilator.

\section{Standard Operative Tracheostomy Group (SOT)}

Twenty-five patients in this group had undergone standard operative tracheostomy.

In this study, Ciaglia Blue Rhino Dilator percutaneous tracheostomy set introduced by Cook Bloomington Inc. were used. Standard surgical instruments were used for operative tracheostomy.

\section{Selection of Cases \\ Inclusion Criteria}

Patients with normal neck anatomy who required endotracheal intubation for more than 15 days.

\section{Exclusion Criteria}

- Age < 15 yrs.

- Patients with uncorrectable bleeding diathesis.

- Bleeding time $>10$ mins.

- Platelet count $<50,000 /$ cumm.

- Prothrombin time $>1.5$ times of reference range.

- Gross distortion of neck anatomy due to goitre, haematoma or previous surgery.

- Obese patients with short neck.

- Any evidence of infection in soft tissue of neck.

- Patients who need positive end expiratory pressure more than $15 \mathrm{~cm}$ of water.

- Patients with documented or clinically suspected tracheomalacia.

\section{Technique}

Percutaneous dilatational tracheostomy done using Ciaglia's Blue Rhino Dilator and standard operative tracheostomy.

Both these techniques were done as a bedside procedure by Otorhinolaryngologists, Chengalpattu Medical College Hospital. The following data were recorded.

\section{Before Tracheostomy}

1. Age and sex.

2. Diagnosis.

3. Number of days on endotracheal intubation.

4. Lowest oxygen saturation.

5. Arterial blood gas analysis: $\mathrm{PaO}_{2}, \mathrm{PaCO}_{2}, \mathrm{HCO}_{3^{-}}, \mathrm{Ph}$.

\section{Intra-operatively}

\section{Duration of Procedure}

It was the time taken from the skin incision to insertion of tracheostomy tube or closure of skin incision.

\section{Haemorrhage}

a. Major bleed

Defined as bleeding that required suture ligation.

b. Minor bleed

Defined as bleeding that lengthened the procedure and was controlled by local compression.

\section{False Passage}

Dilatation or insertion of the cannula outside the tracheal lumen.

1. Resistance to insertion of tracheostomy tube.

2. Transient hypotension is defined as systolic blood pressure less than $90 \mathrm{mmHg}$.

3. Transient hypoxia less than 90 percent oxygen saturation by oximetry.

\section{Postoperatively}

1. Arterial Blood Gas Analysis (after 6 hrs.): $\mathrm{PaO}_{2}, \mathrm{PaCO}_{2}$, $\mathrm{HCO}_{3}^{-}, \mathrm{pH}$.

2. Haemorrhage major and minor bleed.

3. Stromal Infection.

Cellulitis around the stoma with purulent secretion and microbiologically documented bacterial growth.

4. Pneumothorax documented by chest radiograph.

5. Subcutaneous Emphysema documented by chest radiograph.

6. Death mortality directly related to a technique complication during the procedure or later during the stay in Intensive Care Unit.

7. Tracheo-oesophageal Fistula documented by endoscopic examination.

8. Tracheoarterial Fistula.

\section{Followup}

Whether the patient has been successfully decanulated or not was noted.

Tracheal stenosis documented by CT scan neck.

\section{Statistical Analysis}

Statistical analysis of quantitative variables was described as mean deviation and range. Categorical variables are expressed as percentages. Comparisons between mean were performed with ' $\mathrm{Z}$ ' test. In the present study, $\mathrm{P}$ value of 0.05 was considered as level of significance.

\section{RESULTS}

Fifty patients were included in this study, 25 for percutaneous dilatational tracheostomy and 25 for standard operative tracheostomy. The mean age was 37.7 yrs. - 39 were male and 11 were female.

The mean duration of translaryngeal intubation before tracheostomy was 7.5 days.

\begin{tabular}{|c|c|c|c|}
\hline & PDT & ST & Total \\
\hline No. of Patients & 25 & 25 & 50 \\
\hline Male/Female Patients & $22 / 3$ & $17 / 8$ & $39 / 11$ \\
\hline Mean Age (yrs.) & 37.6 & 37.8 & $37.7(18-70)$ \\
\hline No. of Days Intubated (Mean) & 8 & 7 & 7.5 \\
\hline \multicolumn{2}{|c|}{ Table 1. Patient Demographics } \\
\hline
\end{tabular}




\section{Indications for Tracheostomy}

Trauma especially central nervous system injury (58\%) were the most common indication for tracheostomy followed by neurological disorders such as stroke, Guillain-Barre syndrome and Myasthenia Gravis (24\%).

The third most common cause was organophosphorus poisoning $(8 \%)$ followed by pulmonary $(6 \%)$ and cardiovascular disorders (4\%).

\begin{tabular}{|c|c|c|c|}
\hline & PDT & ST & Total \\
\hline $\begin{array}{c}\text { Pulmonary (Pneumonia, Respiratory } \\
\text { Failure) }\end{array}$ & 2 & 1 & $3(6 \%)$ \\
\hline Cardiovascular (Heart Failure, MI) & 1 & 1 & $2(4 \%)$ \\
\hline Neurological (Stroke, GBS) & 6 & 6 & $12(24 \%)$ \\
\hline Trauma (CNS Injury) & 13 & 16 & $29(58 \%)$ \\
\hline Organophosphorus Poisoning & 3 & 1 & $4(8 \%)$ \\
\hline \multicolumn{4}{|c|}{} \\
\hline \multicolumn{4}{|c|}{ Table 2. Indications for Tracheostomy } \\
\hline
\end{tabular}

\section{Duration of Procedure}

The mean duration of percutaneous dilatational tracheostomy was 9.6 minutes (standard deviation 2.12, range 6 to 15 minutes) and standard operative tracheostomy was 22 minutes (standard deviation 4.24, range 18 - 30 minutes). Mean duration of procedure was significantly lower with percutaneous dilatational tracheostomy $(\mathrm{P}<0.05)$.

Lowest 02 saturation before tracheostomy was $93.7 \%$ in percutaneous dilatational tracheostomy and $94 \%$ in standard operative tracheostomy.

\begin{tabular}{|c|c|}
\hline $\begin{array}{c}\text { Type of } \\
\text { Procedure }\end{array}$ & $\begin{array}{c}\text { Mean Duration } \\
\text { (Min) }\end{array}$ \\
\hline $\begin{array}{c}\text { Percutaneous Dilatational } \\
\text { Tracheostomy }\end{array}$ & 9.6 \\
\hline Standard Operative Tracheostomy & 22 \\
\hline P value & $<0.05$ \\
\hline \multicolumn{2}{|c|}{ Table 3 } \\
\hline
\end{tabular}

\section{Intraoperative Complications}

Four patients developed major bleeding in standard operative tracheostomy, whereas none of percutaneous dilatational tracheostomy group patients encountered this complication $(\mathrm{P}<0.05)$.

Minor bleeding was also high in standard operative tracheostomy than percutaneous dilatational tracheostomy. Eight patients developed this complication in standard operative tracheostomy and two in percutaneous dilatational tracheostomy group $(\mathrm{P}<0.05)$.

False passage of tracheostomy tube or dilator was encountered in percutaneous dilatational tracheostomy. Four patients developed these complications in percutaneous dilatational tracheostomy groups, which was statistically significant $(\mathrm{P}<0.05)$. One patient developed resistance to insertion of tracheostomy tube in percutaneous dilatational tracheostomy group.

Three patients in percutaneous dilatational tracheostomy group developed transient hypoxia and transient hypotension as compared with two in standard operative tracheostomy group $(\mathrm{P}>0.10)$.

\begin{tabular}{|c|c|c|c|c|}
\hline Complications & PDT & ST & $\begin{array}{c}\text { Standard } \\
\text { Error of } \\
\text { Proportion }\end{array}$ & P \\
\hline Major bleeding & 0 & $4(16 \%)$ & 2.18 & $<0.05$ \\
\hline Minor bleeding & $2(8 \%)$ & $8(32 \%)$ & 2.22 & $<0.05$ \\
\hline $\begin{array}{c}\text { Resistance to } \\
\text { Insertion of } \\
\text { Tracheostomy } \\
\text { Tube }\end{array}$ & $1(4 \%)$ & 0 & 1.02 & $>0.10$ \\
\hline $\begin{array}{c}\text { Transient Hypoxia } \\
\text { (<90\% } \mathrm{O}_{2} \\
\text { Saturation) }\end{array}$ & $3(12 \%)$ & $2(8 \%)$ & 0.47 & $>0.10$ \\
\hline $\begin{array}{c}\text { Transient } \\
\text { Hypotension }\end{array}$ & $3(12 \%)$ & $2(8 \%)$ & 0.47 & $>0.10$ \\
\hline False Passage & $4(16 \%)$ & 0 & 2.18 & $<0.05$ \\
\hline \multicolumn{4}{|c|}{ Table 4 } \\
\hline
\end{tabular}

\section{Postoperative Complications}

One patient in standard operative tracheostomy group developed major bleeding $(\mathrm{P}<0.10)$ and six patients developed minor bleeding in standard operative tracheostomy group when compared to one in percutaneous dilatational tracheostomy group which was statistically significant $(\mathrm{P}<$ 0.01).

Subcutaneous emphysema was encountered in two patients of standard operative tracheostomy group and none in percutaneous dilatational tracheostomy group. It was not statistically significant.

Seven patients of standard operative tracheostomy developed stromal infection to one in percutaneous dilatational tracheostomy group $(\mathrm{P}<0.05)$.

Post-operative complications were significantly high with standard operative tracheostomy (56\%) compared to percutaneous dilatational tracheostomy group $(8 \%)(\mathrm{P}<$ 0.001).

\begin{tabular}{|c|c|c|c|c|}
\hline Complications & PDT & ST & $\begin{array}{c}\text { Standard } \\
\text { Error of } \\
\text { Proportion }\end{array}$ & P \\
\hline Major Bleeding & 0 & $1(4 \%)$ & 1.02 & $>0.10$ \\
\hline Minor Bleeding & $1(4 \%)$ & $6(24 \%)$ & 2.13 & $<0.05$ \\
\hline $\begin{array}{c}\text { Subcutaneous } \\
\text { Emphysema }\end{array}$ & 0 & $2(8 \%)$ & 1.47 & $>0.10$ \\
\hline Stromal Infection & $1(4 \%)$ & $7(28 \%)$ & 2.67 & $<0.01$ \\
\hline Total & $\mathbf{2}(\mathbf{8 \% )})$ & $\mathbf{1 5}(\mathbf{5 6 \% )}$ & $\mathbf{4 . 2 4}$ & $<\mathbf{0 . 0 0 1}$ \\
\hline \multicolumn{5}{|c|}{ Table 5 } \\
\hline \multicolumn{5}{|c|}{} \\
\hline
\end{tabular}

\section{Arterial Blood Gas Analysis}

Arterial blood gas analysis was done for percutaneous dilatational tracheostomy and standard operative tracheostomy patients. The following results were noted.

Pre-operatively, in percutaneous dilatational tracheostomy group mean $\mathrm{PaO}_{2}, \mathrm{PaCO}_{2}, \mathrm{HCO}_{3}$ - and $\mathrm{pH}$ were $92.44 \mathrm{mmHg}, 40.24 \mathrm{mmHg}, 21.92 \mathrm{mEq}$ and 7.4 respectively.

Postoperatively, the mean values for $\mathrm{PaO}_{2}, \mathrm{PaCO}_{2}, \mathrm{HCO}_{3}$ and $\mathrm{pH}$ were $93.8 \mathrm{mmHg}, 40.8 \mathrm{mmHg}, 22.04 \mathrm{mEq}$ and 7.41 .

Preoperatively and postoperatively, there was no statistically significant difference noted in $\mathrm{PaO} 2, \mathrm{PaCO} 2, \mathrm{HCO}_{3^{-}}$ and $\mathrm{pH}$ in percutaneous dilatational tracheostomy group (P > 0.05).

In standard operative tracheostomy, preoperatively, the mean $\mathrm{PaO}_{2}, \mathrm{PaCO}_{2}, \mathrm{HCO}_{3}$ - and $\mathrm{pH}$ were noted respectively. 


\begin{tabular}{|c|c|c|c|}
\hline No. & $\begin{array}{c}\text { ABG } \\
\text { Parameter }\end{array}$ & Preoperatively & Postoperatively \\
\hline 1. & $\mathrm{PaO}_{2}$ (mean) & 92.44 & 93.8 \\
\hline 2. & $\mathrm{PaCO}_{2}$ (mean) & 40.24 & 40.8 \\
\hline 3. & $\mathrm{HCO}_{3}-\mathrm{mEq}$ & 21.92 & 22.04 \\
\hline 4. & $\mathrm{pH}(\mathrm{mean})$ & 7.4 & 7.41 \\
\hline \multicolumn{3}{|c|}{ Table 6. Percutaneous Dilatational Tracheostomy } \\
\hline
\end{tabular}

In standard operative tracheostomy, preoperatively, the mean $\mathrm{PaO}_{2}, \mathrm{PaCO}_{2}, \mathrm{HCO}_{3}$ - and $\mathrm{pH}$ were $95 \mathrm{mmHg}$, $41.7 \mathrm{mmHg}$, $22 \mathrm{mEq}$ and 7.4 noted respectively.

The mean $\mathrm{PaO}_{2}, \mathrm{PaCO}_{2}, \mathrm{HCO}_{3}$ - and $\mathrm{pH}$ were $95.04 \mathrm{mmHg}$ $43.8 \mathrm{mmHg}, 23.66 \mathrm{mEq}$ and 7.4 were noted postoperatively.

There was no statistically significant difference noted preoperatively and postoperatively in standard operative tracheostomy groups.

\begin{tabular}{|c|c|c|c|}
\hline No. & $\begin{array}{c}\text { ABG } \\
\text { Parameter }\end{array}$ & Preoperatively & Postoperatively \\
\hline 1. & $\mathrm{PaO}_{2}$ (mean) & 95 & 95.04 \\
\hline 2. & $\mathrm{PaCO}_{2}$ (mean) & 41.7 & 43.8 \\
\hline 3. & $\mathrm{HCO}_{3}-(\mathrm{mEQ})$ & 22 & 23.6 \\
\hline 4. & $\mathrm{pH}$ (mean) & 7.4 & 7.4 \\
\hline \multicolumn{3}{|c|}{ Table 7. Standard Operative Tracheostomy } \\
\hline
\end{tabular}

\section{Post-Decannulation Followup}

Nine patients were decannulated in standard operative tracheostomy group and five in percutaneous dilatational tracheostomy group. This parameter was not comparable, because it depends upon the outcome of their primary disease.

Out of nine decannulated patients in standard operative tracheostomy, one patient developed tracheal stenosis. None of five patients in percutaneous dilatational tracheostomy group developed tracheal stenosis $([p>0.10)$.

\begin{tabular}{|c|c|c|c|c|}
\hline Followup & PDT & ST & $\begin{array}{c}\text { Standard } \\
\text { Error of } \\
\text { Proportion }\end{array}$ & P \\
\hline $\begin{array}{c}\text { No. Cases } \\
\text { Decannulated }\end{array}$ & $5(20 \%)$ & $9(36 \%)$ & - & - \\
\hline $\begin{array}{c}\text { Tracheal } \\
\text { Stenosis }\end{array}$ & 0 & $1(11 \%)$ & 1.05 & \begin{tabular}{c}
$>$ \\
\hline \multicolumn{4}{|c|}{ Table 8 }
\end{tabular} \\
\hline \multicolumn{4}{|c|}{}
\end{tabular}

\section{DISCUSSION}

Percutaneous dilatational tracheostomy was developed shortly after Seldinger's important description of needle replacement over a guidewire in arterial catheterisation. In 1955, Sheldon et al first attempted percutaneous tracheostomy with a slotted needle and trocar. Since then, 4 different techniques of percutaneous dilatational tracheostomy have been reported of which Ciglia et al's percutaneous dilatational tracheostomy gained popularity, mainly because of their safety, efficacy and their lower perioperative complications. Recent Ciaglia Blue Rhino Dilator eliminates multiple dilatations by serial dilators and has lower complications than originally described Ciaglia's percutaneous dilatational tracheostomy using multiple dilators.

Tracheostomy has several advantages over prolonged translaryngeal intubation. Better patient's comfort level, early and safe weaning from mechanical ventilation are some to be mentioned.

The mean age group of patients in our study was 37.7 yrs., which ranges from 18 to $70 \mathrm{yrs}$. The mean age was lower than reported in Western studies such as Hazard et al,(3) Crofts et al,(7) Friedman et $\mathrm{al}^{(2)}$ and Holdgaard et al(8) because of our lower life expectancy than western countries.

The average number of days on endotracheal intubation before tracheostomy was 7.5 days in our study. This correlates well with Hazard et al study. Other studies in literature showed longer duration of intubation before tracheostomy.

The most common indication for tracheostomy in our study was traumatic central nervous system injury followed in order by neurological disorder such as stroke, Guillain-Barre syndrome, etc. Organophosphorus poisoning, pulmonary artery and cardiovascular diseases. This contrasts with that of Western studies such as Friedman et al(2) and Holdgaard et al(8) where pulmonary disorders such as pneumonia, respiratory failure, COPD, etc., were the most common indication for tracheostomy followed by neurological and cardiovascular disorders. It is because of our study was conducted at Intensive Care Units. Excluding neurological disorders, organophosphorus poisoning formed the second most common indication for tracheostomy.

Percutaneous dilatational tracheostomy was faster (9.6 minutes) compared to standard operative tracheostomy (22 minutes). This result was comparable to that of Friedman et al(2) and meta-analysis by WE Fee and Elbert Cheng et al.(9)

Bleeding was less frequently encountered in PDT group than ST group. None of the PDT group patients developed major bleeding, two of them developed minor bleeding. Whereas in ST group this was relatively high with major and minor bleeding of $16 \%$ and $32 \%$ respectively. This was the most frequent complication in ST group. The use of a smaller incision, blunt dissection instead of cutting and transecting the blood vessels, dilatation of stoma with Ciaglia Blue Rhino Dilator that causes compression of surrounding blood vessels, while dilating may explain the less frequent and less bleeding in PDT group.

False passage, i.e. paratracheal placement was the most frequent complication in PDT group in our study. It was encountered in four patients (16\%), which was significantly higher percentage than reported in literature (Friedman et al,(2) Errington C. Thompson et al(6)). No paratracheal placement was reported in those studies, which were done under bronchoscopic guidance (Errington C. Thompson et $\mathrm{al}^{(6)}$. The most challenging step in this procedure was placing the introducer needle into the proper location in the anterior trachea. They have stressed the importance of aspirating air during the placement of introducer needle into trachea. This however will not rule out introducer needle in oesophagus. Using bronchoscope guidance can help to prevent this complication (Errington C. Thompson et al(6)).

Resistance to insertion of tracheostomy tube occurred in one patient (4\%). This was not statistically significant.

There was no difference in transient hypoxia and transient hypotension that occurs during the procedure in both the groups. This was $12 \%$ and $8 \%$ respectively in both.

When comparing these techniques, a dramatic difference in overall number of postoperative complications was noted. The PDT group had a lower incidence of complications than the ST group. This was $8 \%$ and $5 \%$ respectively. These rates were comparable with those reported in non-randomised, retro-prospective studies in literature. Complications rate for 
PDT group ranged $5.5 \%$ to $19 \%$ and for ST group from $6 \%$ to $63 \%$ (Hill BB, Zweng TN et al(4) and Gillman GS et al(5)).

The most frequent postoperative complication in the ST group was stomal infection (28\% in ST group versus $4 \%$ in the PDT group). This was statistically significant $(\mathrm{P}<0.01)$ were comparable to that of Hazard et al study (PDT 8\% and ST 33\%). The PDT method incorporates a smaller incision and less dissection of tissue planes, which allowed less vascular and tissue disruption. It may be an explanation for the decreased incidence of stomal infections in percutaneous dilatational tracheostomy.

The second most frequent postoperative complication encountered in standard operative tracheostomy was bleeding. Six patients (24\%) developed minor bleeding and one patient (4\%) developed major bleeding in ST group compared to one patient (4\%) who developed minor bleeding in PDT group. This was statistically significant $(\mathrm{P}<0.05)$. This result was also comparable to that of Hazard et al(3) study.

Two patients in standard operative tracheostomy group developed subcutaneous emphysema, which was confined to neck and resolved simultaneously without any surgical intervention. This may be due to too large incision in trachea, improperly fitting tracheostomy tube or tight skin closure.

In blood gas analysis, there were no significant difference in pre-operative and post-operative values of $\mathrm{PaO}_{2}, \mathrm{PaCO}_{2}$, $\mathrm{HCO}_{3}-$ and $\mathrm{pH}$ of neither percutaneous dilatational tracheostomy nor standard operative tracheostomy.

Five patients (20\%) in PDT group and nine patients (36\%) in ST group were successfully decannulated from tracheostomy tube. Others died due to their primary illness; their dependency on long-term ventilation or they were lost during followup. One patient in standard tracheostomy group developed tracheal stenosis. This was not significant statistically. The long-term complication of tracheal stenosis is not reported in most of the randomised trials. The incidence of tracheal stenosis reported in the literature for PDT was between 0 to $10 \%$ and that for ST was 0 to $16 \%$ (Hill BB and Zweng et al(4) and Law RC et al(10)).

For an acute airway compromise in malignancy may need an emergency airway access method to relieve the airway obstruction. In these situations, either a cricothyroidectomy or emergency tracheostomy may be a life-saving procedure, because percutaneous dilatational tracheostomy is contraindicated for an emergency airway access.

For a proper functioning of tracheostomy tube, postoperative nursing care was needed. Activation of high pressure alarm in ventilator, sudden tachycardia, hypertension, reduced chest movements and 02 saturation may indicate an obstruction in the tracheostomy tube. It needs immediate intervention to relieve obstruction.

Over the past 15 years, the experience with PDT has been reported by numerous teaching hospitals. No significant difference was demonstrated in mortality rate, pneumothorax or other complications. Noticed a trend towards a significantly lower incidence of paratracheal placement when bronchoscopic guidance was used. These findings indicate that PDT can be performed safely in a community hospital with morbidity and mortality rate as low as those reported in large teaching hospitals (Errington C. Thompson, et al(6)).
Issues such as bronchoscopic guidance and costs for PDT were not covered in our study, as we focused solely on the intra- and post-operative complications in percutaneous dilatational tracheostomy and standard operative tracheostomy.

\section{Summary}

- Neurological disorders and central nervous system injury were the most common indication for tracheostomy in intensive care units.

- A five-fold increased rate of post-operative complications occurred in standard operative than percutaneous dilatational tracheostomy.

- Ciaglia's Blue Rhino Dilator provides simple, safe and faster technique for percutaneous dilatational tracheostomy.

- No significant difference in pre-operative and postoperative values of blood gas analysis noted in both percutaneous dilatational and standard tracheostomy.

- No significant difference in long-term complications were found in both these techniques.

- Frequent complications in standard operative tracheostomy like bleeding and stomal infection were less in percutaneous dilatational tracheostomy.

- Percutaneous dilatational tracheostomy is a safe alternative procedure for elective tracheostomy in patients with a normal neck anatomy.

- Standard operative tracheostomy or cricothyroidectomy should be done for patients with abnormal neck anatomy and/or for an emergency access to the airway.

\section{CONCLUSION}

In this comparative study of percutaneous dilatational tracheostomy and standard operative tracheostomy, we conclude that it is a faster technique and a safe alternative to standard operative tracheostomy. Intraoperative and postoperative complications are less with percutaneous dilatational tracheostomy.

\section{REFERENCES}

[1] Ciaglia P, Firshing R, Synies C. Elective percutaneous dilatational tracheostomy. A new simple bedside procedure; preliminary report. Chest 1985;87(6):715-9.

[2] Friedman Y, Flides J, Mizok B, et al. Comparison of percutaneous and surgical tracheostomies. Chest 1996;110(2):480-5.

[3] Hazard P, Jones C, Benitone J. Comparative clinical trial of standard operative tracheostomy with percutaneous tracheostomy. Crit Care Med 1991;19(8):1018-24.

[4] Hill BB, Zweng TN, Maley RH, et al. Percutaneous dilational tracheostomy: report of 356 cases. J Trauma 1996;41(2):238-43.

[5] Gillman GS, MacRae DL. Propective evaluation of endoscopically assisted percutaneous dilational tracheostomy. Journal Otolaryngol 1996;25(6):383-7.

[6] Thompson EC, Fernandez LG, Norwood S, et al. Percutaneous dilational tracheostomy in a community hospital setting. South Med J 2001;94(2):208-11.

[7] Crofts SL, Alzeer A, McGuire GP, et al. A comparison of percutaneous and operative tracheostomies in intensive care patients. Can J Anasth 1995;42(9):775-9. 
[8] Holdgaard HO, Pederson J, Jensen RH, et al. Percutaneous dilatational tracheostomy versus conventional surgical tracheostomy. A clinical randomized study. Acta Anesthesiol Scand 1998;42(5):545-50.

[9] Cheng E, Fee WE. Dilatational versus standard tracheostomy: a meta-analysis. Ann Otol Rhinol Laryngol 2000;109(9):803-7.
[10] Law RC, Carney AS, Manara AR. Long-term outcome after percutaneous dilational tracheostomy. Endoscopic and spirometry findings. Aneasthesia 1997;52(1):51-6. 